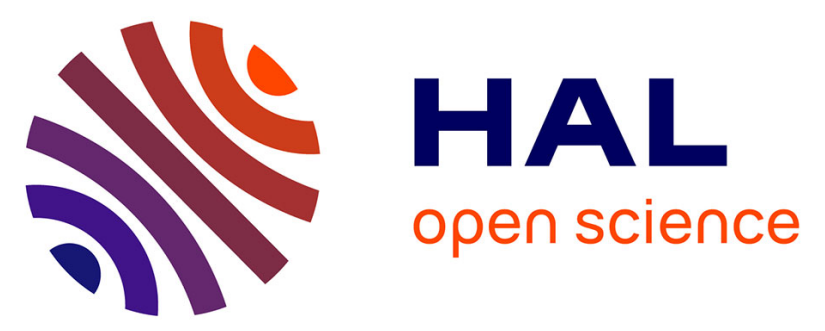

\title{
3D musculo-skeletal finite element analysis of the foot kinematics under muscle activation with and without ankle arthrodesis
}

\author{
Antoine Perrier, Marek Bucki, Vincent Luboz, Nicolas Vuillerme, Yohan \\ Payan
}

\section{To cite this version:}

Antoine Perrier, Marek Bucki, Vincent Luboz, Nicolas Vuillerme, Yohan Payan. 3D musculo-skeletal finite element analysis of the foot kinematics under muscle activation with and without ankle arthrodesis. Computer Methods in Biomechanics and Biomedical Engineering, 2015, 18 (S1), pp.2022-2023. 10.1080/10255842.2015.1069605 . hal-01235940

\section{HAL Id: hal-01235940 \\ https://hal.science/hal-01235940}

Submitted on 1 Dec 2015

HAL is a multi-disciplinary open access archive for the deposit and dissemination of scientific research documents, whether they are published or not. The documents may come from teaching and research institutions in France or abroad, or from public or private research centers.
L'archive ouverte pluridisciplinaire HAL, est destinée au dépôt et à la diffusion de documents scientifiques de niveau recherche, publiés ou non, émanant des établissements d'enseignement et de recherche français ou étrangers, des laboratoires publics ou privés. 


\title{
3D musculo-skeletal finite element analysis of the foot kinematics under muscle activation with and without ankle arthrodesis
}

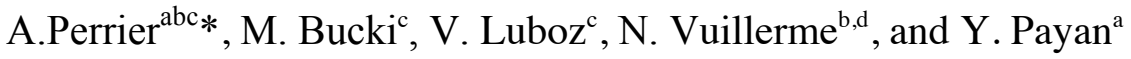

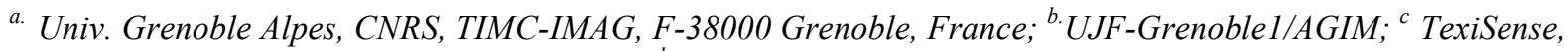 \\ Montceau-les-Mines, France ; ${ }^{d}$ Institut Universitaire de France, Paris, France ;
}

Keywords: Foot model; Finite Element; Musculoskeletal; Motion Analysis; Arthrodesis

\section{Introduction}

The choice between arthrodesis and arthroplasty in the context of advanced ankle arthrosis remains a highly disputed topic in the field of foot and ankle surgery. Arthrodesis, however, represents the most popular option. Biomechanical modeling has been widely used to investigate static loading of cadaveric feet (Valderrabano et al. 2003) as well as consequences of arthrodesis on bony structures. Although foot kinematics has been studied using motion analysis, this approach lacks accuracy in capturing internal joints motion due to limitations inherent to external "marker sets" and the fact that it imposed the foot to be considered as a rigid solid. The consequences of arthrodesis on kinematics of the unloaded foot are not well understood although it is of crucial importance during the swing phase and at heel contact. Investigating ankle mobility during muscle contraction with and without arthrosis could explain how the motion is produced by extrinsic muscles activations affected by an arthrodesis. This study aims at defining if a biomechanical model with Finite Elements (FE) could help arthrodesis understanding.

\section{Methods}

\subsection{Modeling}

A multi-body musculoskeletal model of the foot has been developed using the ArtiSynth simulation platform (Lloyd et al. 2012). The model features rigid bodies modeling the bones and joint interactions as well as FE modeling the soft tissues of the foot.

- Musculoskeletal model

A high-resolution CT volume acquired on the unloaded right foot of a patient was used to segment the 30 bones and reconstruct their 3D shapes. Rigid body contact constraints have been implemented in the Artisynth framework to model joint interactions. All 33 joint motions are further constrained by 210 ligaments modeled by cables and inserted on the bones using CT images of the patient. The foot model does not rely on idealized joint models but solely on the modeling of contacts between bones and of ligaments attached to the bones in order to guide the foot kinematics. The Aponeurosis has been modeled using five ligaments linked by transverse structures. Finally, 15 Hill's model muscles have been positioned according to their anatomical course and can be independently activated (Fig 1).

- Finite Element model

Soft tissues have been modeled by a FE mesh comprising three sub-domains representing skin, fat and muscles tissues. The resulting mesh has 78,161 elements $(21,900$ hexahedrons, 17,319 pyramids, 22,304 tetrahedrons, and 16,638 wedges) and 47,242 nodes. Neo-Hookean materials were used to account for large deformations. Each soft-tissue sub-domain implements the relevant mechanical properties, namely: $\mathrm{E}=200 \mathrm{kPa}, v=0.485$ for the skin; $\mathrm{E}=60 \mathrm{kPa}$, $\nu=0.495$ for muscles; and $\mathrm{E}=30 \mathrm{kPa}, v=0.49$ for fat tissues (Fig 2). All the modeled elements are subject to gravity.

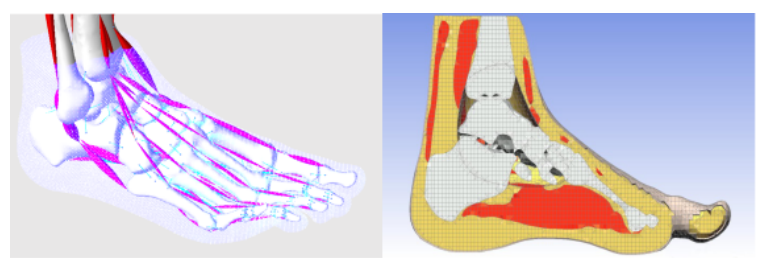

Fig 1: Musculoskeletal (left) and finite element (right) parts of the foot model.

\subsection{Simulation}

A simulation using hill's muscle activation patterns for dorsal and plantar flexion of the ankle with and without arthrodesis was carried out. Muscles are activated by shortening their length. The mobility of the talus bone and the foot was assessed using kinematic measurements.

Dorsal flexion activation patterns initiate the foot movement by first contracting muscles that enable the dorsal flexion of the ankle (Tab 1, top lines):

*Corresponding author. Email: antoine.perrier@imag.fr 
1) The first simulated movement features the activation of toes and hallux extensor muscles alone, followed by a return to a resting position.

2) The second involves the contraction of the tibialis anterior muscle alone, followed by a return to a resting position.

3) The third simulated movement is driven by the synergistic contraction of the extensors and the tibialis anterior.

Plantar flexion activation patterns initiate the foot movement by first contracting muscles that allow the plantar flexion of the ankle (Tab 1, bottom lines):

1) The first simulated movement features the activation of toes and hallux flexor muscles alone, followed by a return to a resting position.

2) The second involves the contraction of the tibialis posterior muscle alone, followed by a return to a resting position.

3) The third simulated movement involves the contraction of the triceps, followed by a return to a resting position.

4) The fourth simulated movement is driven by the synergistic contraction of all those ankle flexor muscles.

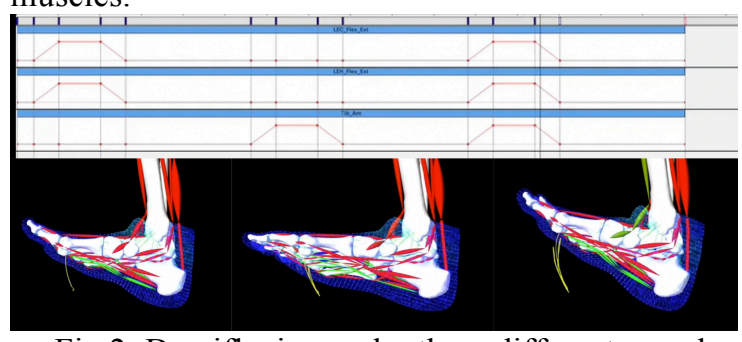

Fig 2: Dorsiflexion under three different muscle activations.

\subsection{Evaluation}

The 3D angle called hereafter "Foot motion", formed by the mass center of the tibia, the mass center of the talus and the center of the second metatarsal head, is considered as an anatomical axis of the foot. In the simulations performed with arthrodesis, only the first 3D angle, called hereafter "Ankle fusion - Foot motion", was computed given that the tibia-talus angle was set to $117^{\circ}$ by the simulated joint fusion. Angle measurements were also performed in 2D after projecting the reference points on the three anatomical planes. Movements were split into:

- Dorsal/plantar flexion in the sagittal plane,

- Pronation/supination in the frontal plane, and

- Abduction/adduction in the horizontal plane.

These three categories are made to facilitate a clinical interpretation of the results.

\section{Results and discussion}

The combined action of the anterior muscles induces a 3D dorsal flexion with peak values: Foot motion $=$ $42.2^{\circ}$. In this activation pattern, the arthrodesis limits dorsal flexion to Ankle fusion - Foot motion $=8.7$.
The combined action of the posterior muscles induces a 3D plantar flexion with peak values: Foot motion $=$ $32.7^{\circ}$. With the arthrodesis, 3D plantar flexion is Ankle fusion - Foot motion $=14.4^{\circ}$.

By simulating a virtual arthrodesis, the biomechanical model makes it possible to explore the relationships between adjacent joints and to quantify their respective amplitudes within a foot motion. Hence the contraction of the TA muscle alone ( $2^{\text {nd }}$ movement) with the arthrodesis makes it possible to compute the mobility of the navicular on the talus. Indeed, $2.8^{\circ}$ movement (Ankle fusion - Foot motion angle in the sagittal plane during dorsal flexion) is produced by the navicular alone since the talus is fixed. The missing Ankle fusion - Foot motion amplitude in the sagittal plane (i.e. $8.7^{\circ}-2.8^{\circ}=5.9^{\circ}$ ) is provided through the Cuneo-metatarsal and Cuneo-navicular joints, which are mobilized by the synergistic contraction of anterior muscles

\begin{tabular}{|c|c|c|c|c|}
\hline \multirow{2}{*}{$\begin{array}{l}\text { Dorsal } \\
\text { Flexion }\end{array}$} & $\begin{array}{c}\mathrm{EHL}+\mathrm{E} \\
\mathrm{DL}\end{array}$ & TA & $\begin{array}{c}\text { EHL+EDL+ } \\
\text { TA }\end{array}$ & \\
\hline & $3 \mathrm{D}$ & $3 \mathrm{D}$ & $3 \mathrm{D}$ & \\
\hline $\begin{array}{l}\text { Foot motion peak } \\
(\text { FMP })\left({ }^{\circ}\right)\end{array}$ & 35.2 & 27.4 & 42.2 & \\
\hline $\begin{array}{l}\text { Ankle fusion foot } \\
\text { motion peak } \\
(\text { AFFMP })\left({ }^{\circ}\right)\end{array}$ & 5.8 & 2.8 & 8.7 & \\
\hline \multirow[t]{2}{*}{$\begin{array}{l}\text { Plantar } \\
\text { Flexion }\end{array}$} & $\begin{array}{l}\text { FHL+ } \\
\text { FDL }\end{array}$ & TP & Triceps & $\begin{array}{c}\text { FHL+ } \\
\text { FDL+ } \\
\text { TP+ } \\
\text { Trice } \\
\text { ps }\end{array}$ \\
\hline & $3 \mathrm{D}$ & $3 \mathrm{D}$ & $3 \mathrm{D}$ & $3 \mathrm{D}$ \\
\hline FMP $\left(^{\circ}\right)$ & 15.4 & 13.5 & 26.3 & 32.7 \\
\hline $\operatorname{AFMP}\left({ }^{\circ}\right)$ & 10.5 & 7.1 & 1.9 & 14.4 \\
\hline
\end{tabular}

Tab 1: 3D Foot motion with and without arthrodesis under muscle activation. Extensus (E), Flessor (F),

Hallucis Longus (HL), Digitorum Longus

(DL), Tibialis Anterior (TA), Posterior (TP)

\section{Conclusion}

A patient-specific model of the foot with and without simulated arthrodesis, driven by muscle activations reproducing the swing motion of the foot, could be used for surgical planning to find the optimal setting of the tibio talar angle in order to optimize swing phase during gait.

\section{References}

Valderrabano, V., Hintermann, B., Nigg, B. M., Stefanyshyn, D., Stergiou, P. 2003. Kinematic changes after fusion and total replacement of the ankle: part 3: Talar movement. Foot \& Ankle International 24(12), 897-900

Lloyd, J. E., Stavness, I., Fels, S. 2012. ArtiSynth: A Fast Interactive Biomechanical Modeling Toolkit Combining Multibody and Finite Element Simulation. Soft Tissue Biomechanical Modeling for Computer Assisted Surgery (pp. 355-394). 